\title{
Infant Health and Care: An Urban Perspective
}

\section{ISSN: 2576-9200}

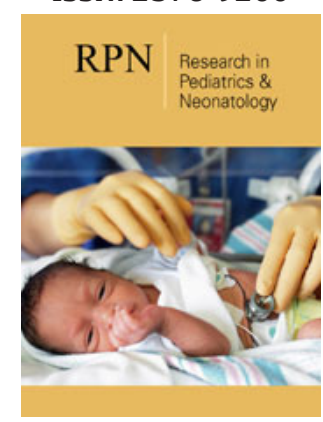

*Corresponding author: Neetu Choudhary, Amity University Patna, India

Submission: 梅 September 19, 2020

Published: 址 November 03, 2020

Volume 5 - Issue 1

How to cite this article: Neetu Choudhary. Infant Health and Care: An Urban Perspective. Research in Pediatrics \& Neonatology. 5(1). RPN. 000602. 2020. DOI: $10.31031 /$ RPN.2020.05.000602

Copyright $(\subset$ Neetu Choudhary. This article is distributed under the terms of the Creative Commons Attribution 4.0 International License, which permits unrestricted use and redistribution provided that the original author and source are credited.

\author{
Neetu Choudhary ${ }^{1,2 *}$ \\ ${ }^{1}$ Amity University Patna, India \\ ${ }^{2}$ Arizona State University, USA
}

\section{Introduction}

Nearly 90 percent of the projected urban population increase is concentrated in Africa and Asia [1]- regions that harbour majority of world' malnourished children today. Approximately one in three undernourished children now live in urban settings and in 13 countries urban stunting rates are above $30 \%$ [2]. Broad evidences exemplify that malnutrition in urban areas is a growing reality [3], though there is a dearth of studies in this regard. In terms of infant nutrition, we have far little evidences. In a relatively early work using Demographic and Health Survey (DHS) data for 43 countries [4-6] showed that in Latin American and Caribbean countries young children in big cities have stunted growth while in Asian countries children in large cities did not reflect a remarkable advantage over those in small cities or rural areas. However, in a recent study on 26 countries' data, [7] found that the large urban areas of developing countries have lower infant mortality and malnutrition levels. While this could be average picture for urban areas, infant health and nutrition among the urban poor is likely as big a challenge as among the rural counterparts. This can be explained in terms of growing inequality and disparity in urban areas [8-10], due to which a considerable population segment perpetuates on the periphery amidst overall prosperous urban landscape.

Moreover, we have enough evidence today that call for more affirmative action towards infant health and nutrition among the urban poor. Infant health and nutrition in urban areas need separate research and policy attention because, the urban dimension of infant health is different from the rural one in several ways, as discussed here.

\section{Market as The Central Player}

Market plays a key role in urban areas and it affects infant health through multiple pathways and a chain of consequences. To begin with, in urban areas for every basic need people rely on cash based exchanges. Poor people have an obvious disadvantage in this regard, as they have to face trade-offs between which needs are to be met and which are to be foregone. Consequently, their access to safe food, drinking water and sanitation is hugely compromised. Lack of household food and water security is detrimental to infant nutrition. While the link between food and nutrition is well established, the role of household water insecurity in shaping up child's access to optimal diet is only recent studied [11]. Water insecurity, which is a major by-product of growing urbanization, is not only a major challenge for child health through mechanisms of WASH (leading to infections and diarrhoea) [12] but also results into child's sub-optimal access to complementary feeding [11].

Secondly, greater dependence upon cash in urban areas, requires both parents to engage in paid employment, which means that caregivers-usually mothers- have less time for their children [13]. This again affects infant's dietary diversity and health care negatively. Caregivers' time becomes scarce in urban areas, as women get involved in employment outside home and face greater resource challenge. For example-household water management burden diverts women's time away from preparing diverse and frequent meal for their infants [14]. While first two years of a child after birth, is critical for her growth, infants in urban poor households escape due attention. Often, elder siblings are all they have for being attended to. 


\section{The Urban Resource Challenge}

Population growth is happening fastest in urban areas of less developed regions, and alongside planning and infrastructure have been unable to keep pace with water and sanitation needs in many regions. When resources are limited, it is the poor, especially those in informal settlements, who have to go without it since they can't afford to purchase as much as required. Today, 700 million urbanites live without improved sanitation, contributing to poor health conditions and heavy pollution loads in wastewater, and 156 million live without improved water sources (WHO 2017). Migrants in urban areas especially short duration migrants are particularly vulnerable to resource insecurities since they don't have any rights' claim. Due to challenges associated with adaptation, they are often denied basic amenities [15]. The lack of safe water and sanitation is the most common channel to create infections among infants and push them into the cycle of malnutrition. Urban poor and migrant communities are highly susceptible to this.

Furthermore, even if resources such as health facilities are easily available in urban areas, they are not accessible by the poor. Poverty becomes a barrier in accessing required health services especially when the government supported health facilities are not effective and friendly.

\section{Women's Work and Infant Health}

Role of women is already intertwined with the challenges posed by market and resource challenge. Due to women's primary role as mother and caregiver, any increase in food or water crisis implies increase in their work burden, which will eventually result in inadequate dietary diversity, lack of complementary feeding and poor care practices for their infants and young children. Social capital and kinship networks are weaker in urban areas and often women are under tremendous work burden. Women's own health is also at risk due to exposure to poor living and working environment and lack of balanced diet and care, which is translated to infants through the reproductive relationship. Interestingly, amidst the somewhat chaotic urban context of the developing world, the trend of dietary transition is strongly visible [1]. In urban areas there is greater availability of cheap street food, which is often substituted for healthy home meal, but is a very harmful for young children. This is happening both due to lack of caregivers' time and changing dietary preferences associated with urbanization.

Evidently, the urban dynamics underlying infant health and nutrition is complex and various factors play out differently in different socioeconomic and political contexts. These situations vary across contexts, but broadly urban infant health dynamics is quite complex. A decade later or so, the challenge is likely to be highly magnified with growing population and infrastructure constraints. Accessing sanitation and safe water-likely will be the most difficult task in an urbanizing world amidst climate change. It is critical that that the newly urbanizing countries tailor their policies in light of unique characteristics of infant health and nutrition challenges in urban areas. Pediatrics and neonatal health strategy and management systems need to accommodate these contextual realities during program design and implementation. Infant health strategies that work in the countryside, might not be effective in all urban settlements.

\section{References}

1. Fan S (2017) Food security and nutrition in an urbanizing world, Global Food Policy Report, International Food Policy Research Institute, Washington DC, USA.

2. GPAFSN (2017) Urban diets and nutrition: Trends, challenges and opportunities for policy action. Global Panel on Agriculture and Food Systems for Nutrition. London, UK.

3. Ruel MT, Garrett JL, Sivan Y (2017) Food security and nutrition: Growing cities, new challenges. Global Food Policy Report, International Food Policy Research Institute: Washington DC, USA.

4. Ahmed AU, Hill RV, Smith LC, Wiesmann DM, Frankenberger T, et al. (2007) The world's most deprived: Characteristics and causes of extreme poverty and hunger. International Food Policy Research Institute, Washington DC, USA.

5. Brockerhoff M, Brennan E (1998) The poverty of cities in developing regions. Population and Development Review 24(1): 75-114.

6. Brown AM (2014) Uganda's emerging urban policy environment: Implications for urban food security and urban migrants. Urban Forum 25: $253-264$.

7. Rutstein SO, Staveteig S, Winter R, Yourkavitch J (2016) Urban child poverty, health, and survival in low-and middle-income countries. DHS Comparative Reports No. 40, Rockville, Maryland, USA.

8. Ejike CE (2016) Malnutrition affects the urban-poor disproportionately: A study of Nigerian urban children of different socio-economic statuses. Children 3(4): 1-10.

9. Garenne M (2010) Urbanization and child health in resource poor settings with special reference to child mortality evidence in Africa. Arch Dis Child 95(6): 464-468.

10. Montgomery MR and Hewett PC (2005) Urban poverty and health in developing countries: Household and neighborhood effects. Demography 42(3): 397-425.

11. Choudhary N, Schuster R, Brewis A, Wutich A (2020) Water insecurity potentially undermines dietary diversity of children aged 6-23 months: Evidence from India. Maternal \& Child Nutrition 16(2): e12929.

12. Wolf J, Ustün AP, Cumming O, Bartram J, Bonjour S, et al. (2014) Systematic review: Assessing the impact of drinking water and sanitation on diarrhoeal disease in low-and middle-income settings: Systematic review and meta-regression. Tropical Medicine \& International Health 19(8): 928-942.

13. Chase C, Bahuguna A, Chen Y, Haque S, Schulte M (2019) Water and Nutrition: A Framework for Action. World Bank, Washington, DC, USA.

14. Schuster RC, Butler MS, Wutich A, Miller JD, Young SL, et al. (2020) If there is no water, we cannot feed our children: The far-reaching consequences of water insecurity on infant feeding practices and infant health across 16 low- and middle-income countries. American Journal of Human Biology 32(1): 1-24.

15. Neetu C (2015) Malnutrition in Mumbai slums: Entitlement analysis of group differentials in basic capabilities. South Asia Research 35(3): 280297.

For possible submissions Click below: 